\title{
Change your Service Policies Based on your Data
}

\section{Zheng Ye (Lan) Yang}

To cite this article: Zheng Ye (Lan) Yang (2018): Change your Service Policies Based on your Data, Journal of Interlibrary Loan, Document Delivery \& Electronic Reserve

To link to this article: https://doi.org/10.1080/1072303X.2018.1531100

曲 Published online: 20 Nov 2018.

Submit your article to this journal $2 \pi$

View Crossmark data ־ 


\title{
Change your Service Policies Based on your Data
}

\author{
Zheng Ye (Lan) Yang \\ Texas A\&M University Libraries, College Station, Texas, USA
}

\begin{abstract}
Texas A\&M University (TAMU) Libraries' free "Get it for me" service is popular and appreciated by its students and faculty alike. Nevertheless, we noticed many items were not picked up after receipt. In the spring semester of 2016, for each item not picked up, we emailed our customers to ask why they did not come to pick up their requests. Based on the data, we made service policy changes in the summer semester of 2016. As a result we saw a decrease in not picked up rate since. This paper explains the methods we used to achieve this improved results.
\end{abstract}

\section{KEYWORDS}

eBook preference; interlibrary loan items not picked up; interlibrary loan textbook; policy changes; reasons for interlibrary loan cancellation; use interlibrary loan data

\section{Introduction}

Working in the resource sharing field is undoubtedly the most rewarding experience. We have wowed our customers, and we have received unsolicited compliments, such as "your service is the best since sliced bread." "You folks have been magnificent! Thank you for trying" "I cannot fully express in typed words how helpful your service has been for me during my time at the university. This service is entirely user-friendly: the online request form is instantly populated as soon as I move from a library search of a document to the form; the library's automated reminders to pick up books or return checked out books on time are always appreciated: you even retrieve books from the stacks for us and place them in our home library for pick up - this is what I call SERVICE!" (Yang, Hahn, \& Thornton, 2012).

We appreciate and value the sense of cooperation that the very name of our job suggests: instead of competing, we are cooperating and sharing. We play an indispensable part in the academic success of our community. We are truly one of the most important services that our libraries offer.

As much as we would like to continue to deliver a Rolls-Royce "Get it for me" service to our customers by offering free interlibrary loan and inhouse document delivery service, our budget has its limits. 
We have always been frustrated to notice that many of the items that we got for our customers from another library were not ultimately picked up and checked out even though we sent email reminder to them every seven days until five days before its due date. This was a total waste for all parties involved, from shipping cost to manpower. Something must be done. We decided to keep a spreadsheet to record each item that was not picked up by our customers.

\section{Literature review}

A scan of the literature yields no study that has addressed the issue as why customers ultimately decide not to come to pick up their requested items. Many papers used their ILL data to respond to various issues they faced, to understand their customers' use patterns, and to analyze trends in their receipts of requests. Gibson (2008) looked into their 26,800 canceled lending transactions to determine the reasons for cancelation. After the study, they changed their retrieval methods and verification techniques, they saw an improvement in their lending fill rates. Murphey and Greenwood (2009) reviewed all of their 88,376 interlibrary loan requests since 2001 and discovered that the "fastest-growing reason for cancellation of an ILL request is availability in the stacks." They identified the root of the problem and determined instruction needs to mitigate the phenomenon. Likewise, Reycraft (2010) studied their interlibrary loan requests completed either as requests finished or canceled during the third quarter of fiscal year 2008-2009. The author reported that $32 \%$ of the canceled requests were in fact held and available locally. The author discussed why this might be happening; what can be done to reduce such numbers. Tolppanen and Derr (2010) examined 3,074 borrowing requests completed over a three-year span to understand their customer behavior in submitting requests and the types of materials being requested. Grevatt (2015) detailed their efforts to explore the downward trend in their overall requests between 2010 and 2015. Using the ILLiad web reports, the author discovered the contributing factors for the decrease in borrowing and lending requests.

The undertaking study attempts to fill this void in the literature.

\section{Methodology}

Before we returned the not picked up books, we sent an email to our customers, asking them why they did not pick up their requested items. The spreadsheet contains the following data: transaction number, status of the requestor, date the request was submitted, date the item was received, date the customer was notified, reasons for not picking up. 


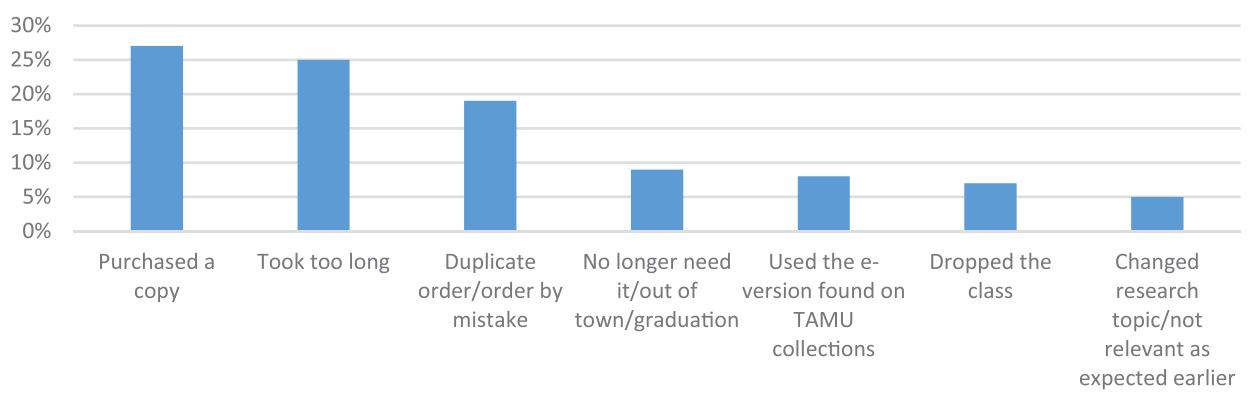

Figure 1. Reasons for not picking up.

\section{Findings}

During the spring semester of 2016, we filled 11,368 loans, however, 1,231 items were not picked up, and that translates to $10.8 \%$ of the items not picked up by our customers.

Texas A\&M University (TAMU) Libraries participated in an ILL cost study conducted by Leon and Kress (2012). That study focuses on unit costs. Data collected was from July 1, 2010 through June 2011. Twentythree medium to large academic libraries took part in the study. Categories used to calculate unit cost per request in the study were staffing, equipment, copyright, payments to supply libraries or other sources, payments received from requests fulfilled, management tools (e.g., ILLiad), request systems (e.g., OCLC, RAPID), shipping costs, and supplies. Microsoft Access database is the mean to enter the data and create the report. The final report revealed that the average cost of a filled loan request on the borrowing side for TAMU Libraries is $\$ 12.02$. With those 1,213 items received but not picked up, this was a waste of $\$ 14,580$.

Figure 1 shows the reasons responded by the requestors as why they did not come to pick up their requested items. $27 \%$ stated that they purchased a copy, mostly because it took too long. $25 \%$ thought it took too long, but they did not indicate that they purchased a copy. 19\% revealed that they made duplicate orders or ordered by mistake. 9\% let us know that they were out of town when the book came in, or they were about to graduate, so there was no need for the book any more. $8 \%$ reported that they used the e-book version instead. $7 \%$ replied that they dropped the class. 5\% noted they changed the research topic.

Zeroing in to the reason "took too long." We wanted to know how long is considered "too long" in the minds of our customers. The spreadsheet includes data such as: the date the customer submitted the request to the date we received the item from the lending library and notified the customer for pick up. The following responses as depicted in Figure 2 show what our customers think about a long waiting time. 


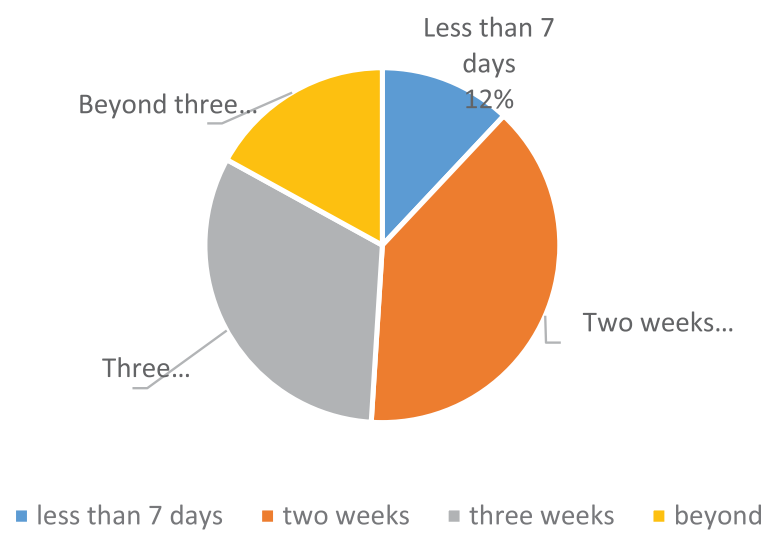

Figure 2. How long is considered too long.

$12 \%$ of our responding customers felt that if they had to wait for a week, it was too long. In this case, we might have spoiled these customers. They might have been used to fast turnaround time, thanks to our Greater Western Library Alliance and SEC consortium members' commitment to delivering items to the requesting libraries within 5 business days. The majority of our requested loans do get to us within that time frame. $39 \%$ of the respondents regarded two weeks as too long. While $32 \%$ considered three weeks of waiting to be too long, and 17\% thought more than three weeks was too long.

From the data, we further examined those customers who opted to purchase their own copy instead of picking up their requested loan items. We realized that many requested items were also available in our Course Reserve for a 4-hour check out only, thus some of our students tried to secure a copy from another library so that they could keep it for a longer period of time. Nevertheless, after waiting for a week or so, they went ahead to purchase a copy themselves instead of waiting for the item's arrival.

\section{Policy changes based on the data}

Based on the data collected, we made the following policy changes:

For items kept in our Course Reserve, instead of immediately ordering from other libraries for our customers, we cancel the request first, with the following message: "We do not retrieve textbooks kept in Course Reserve. It could take weeks with no guarantees to get it from another library. Please respond to this email if you still want us to try."

If a customer requests a print book, but we have an e-version. We do not ask for a print copy from another library for the customer right away. Instead, we cancel the request with the following reason: "For expediency, 
please use the following link to access this eBook owned by TAMU Libraries. If you would still like us to order the print version, please respond to this email. In the future, if you only want a print book, please leave a note in the note field as 'print book only"'.

If the requested item is not on the shelves, instead of immediately ordering a copy from another library, we cancel first with the reason: "The book is not on the shelves, do you want us to request it from another library?"

Those policy changes took effect on June 1, 2016. The email clarification now helps the customer make a conscious, informed choice. Some thanked us for reaching out to them, others apologized for their change of mind of not picking up the items. We now see more customers using the note field to let us know that they only want a print book; or that if the book is not on the shelf, then we ought to request it from another library; or that they are aware that the book is in our reserve, but still want us to try to get it from another library. These assists us in processing their requests faster by cutting out the back and forth email communications.

\section{Policy changes made a difference}

We have continued to tally items not picked up so that we can evaluate if such policy changes have made a difference. Looking at data from June 1 to Dec. 31, 2016, we are pleased to report that we saw a drop of items not picked up by fact of one third. The not picked up rate was down from $10.8 \%$ to $7.7 \%$ (i.e., 1,231 or $10.8 \%$ not picked up out of 11,368 filled loans recorded in the spring semester of 2016 before the policy changes down to 949 items not picked up out of 12,319 filled loans after the policy changes from June 1 to Dec. 31, 2016.).

A year later, using the same date range, June 1, 2017 to Dec. 31, 2017, the not picked up rate was decreased to only $5.3 \%$, a whopping $50 \%$ reduction overall (i.e., 599 items were not picked up from 11,252 filled loans in comparison to 1,231 items not picked up out of 11,368 filled loans before the policy change took place.) Figure 3 reveals a clear picture.

\section{Reasons for not picking up after policy changes}

Evaluating the reasons that customers still did not pick up their items after the policy change, we found that they mirrored the original findings, the top two reasons given were still "purchased a copy" and "took too long," both represented by $27 \%$. 


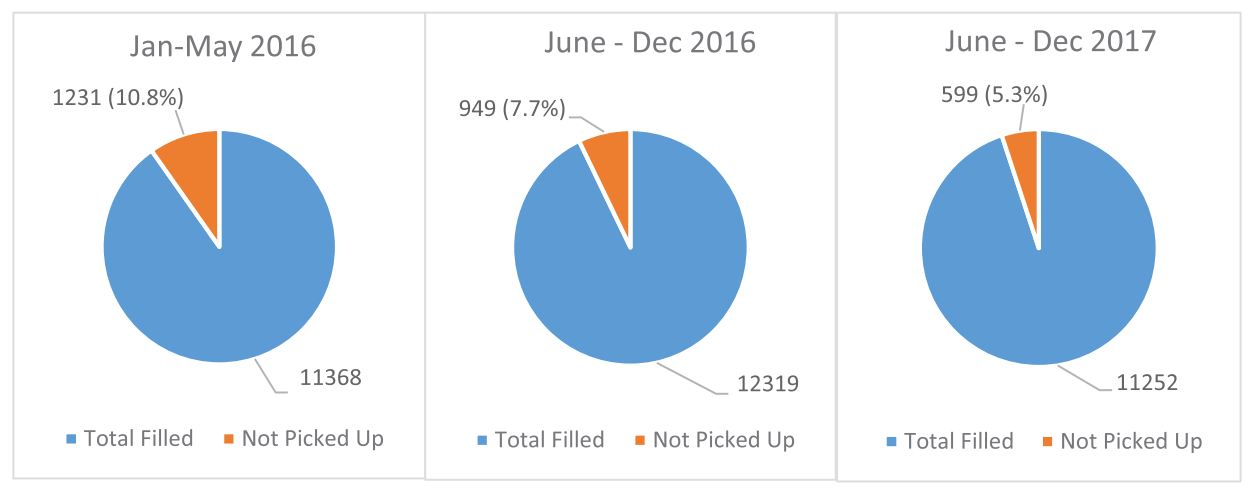

Figure 3. Comparison of not picked up.

\section{Why Texas A\&M allows textbook request}

You might wonder why we still allow our students to request items in our Course Reserve. The main reason we allow this is that our filled rate for requesting "textbooks" from other libraries has always been high, contrary to the assumptions by colleagues that it is difficult to borrow textbooks from another library. Data collected from our study period revealed a stunning $97 \%$ filled rate for textbook requests. This filled rate is much higher than the 56\% textbook filled rate reported in Munson and Savage's 2013 study.

Data also reveals that even when we canceled the requested item that was available in our Course Reserve, $50 \%$ of our students still asked us to get it from another library, even knowing it could take weeks with no guarantee of arrival. This affirms the findings reported by Blackburn and Tiemeyer (2013) that their surveyed students "would prefer to borrow a book they can take home rather than use for a short time inside the library." The data further suggests that once our students confirmed they wanted the textbook copy from another library, only $4.7 \%$ ( 6 books out of 127) were not picked up during the study period. This low not picked up rate mirrors the findings for books not on the shelves. After we emailed them if they would still like us to borrow from another library, 74\% responded with a yes, and when we got those books for them, only $4 \%$ of the books ( 6 books out of 135) were not picked up.

\section{Our customers' format preference}

Our e-preferred approval plan policy has been in place for several years, and we have always wanted to determine how receptive our customers who have used our "Get it for me" services have been to this practice. ILL data can certainly offer some insights. According to our loan requests, as displayed in Figure 4, 90\% of our customers still wanted print books, only $8 \%$ 


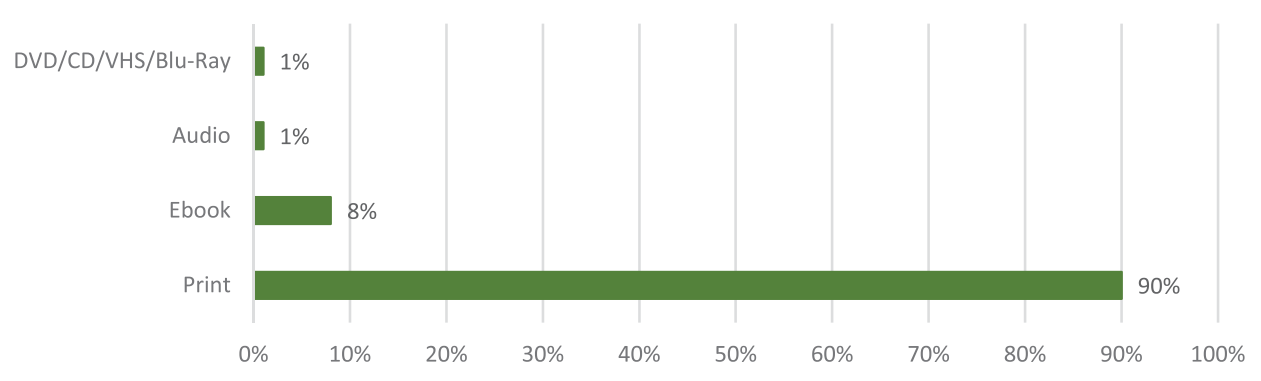

Figure 4. Customers' format preference.

asked for eBooks, $1 \%$ requested audio books and another $1 \%$ asked for DVD/C/VHS/Blu-Ray.

During the fall semester of 2017, we canceled 327 print book requests because we found eBook versions in our collections, and we sent the link of the eBook to our customers for access. Nevertheless, $61 \%$ of the customers responded to the email indicating that they still wanted us to get them a print copy, and did not want an eBook version. This revelation is in contrast with Riha and LeMay's (2016) study, they found their customers appear to use eBooks over print materials when the library provides a choice.

We requested 198 print books out of this category for our customers. The filled rate was $95 \%$. Out of the 188 books we got for our customers from other libraries, (all of which were also available as eBooks in our collections), 27 books or $14 \%$ were not picked up. This is much higher than our overall $5.3 \%$ not picked up rate. That might indicate that if our customers waited for longer than their perceived "acceptable wait period," they would just use the eBook instead. This is a potential policy that we can implement in the future that could possibly reduce some expenses, that is, if we already have a title in one format, we will not spend money to acquire another format unless the customer has a special need.

\section{More workflow changes}

With three full semesters of data, we made one more workflow change in mid-March of this year, hoping to further reduce our not picked up rate and save some costs. For a loan request, if a title has been in the Request Sent status for two weeks, and the lending library has not yet updated the item as "shipped," we email the customer to confirm that they still want the item. If they respond that they no longer need it, we then cancel it. ILLiad lets us sort requests by fields, such as request type, transaction date, due date, and so forth, so that we can accomplish such a task easily.

Data collected in the short three months reveals that there were 136 submitted loan requests that were not filled yet within 2 weeks. We sent 


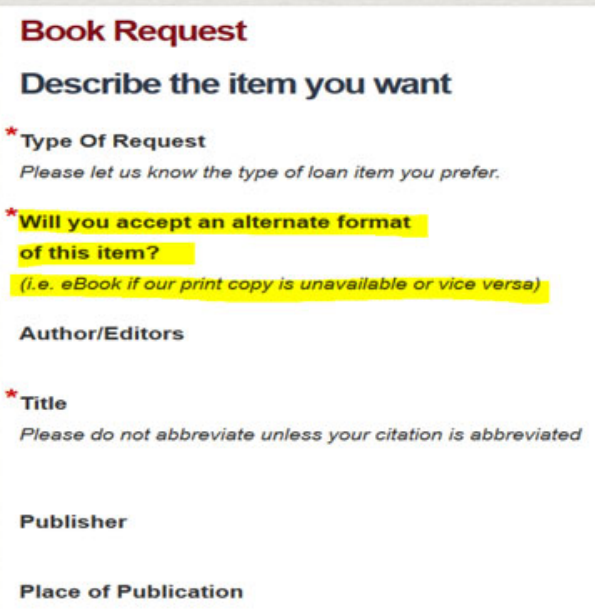

* Indicates required field

Figure 5. Format choice added in the loan request form.

follow-up emails to confirm if our customers were still interested in getting their requested items. Ultimately, twenty five requests (18.4\%) were unfilled. The remaining 97 requests were filled. This filled rate mirrors our overall loan requests' filled rate. However, there were still 7 items that were not picked up by our customers, yielding a $7.2 \%$ not picked up rate. With such a short testing period (three months only), it is too early to assume that the new practice indeed would improve the not picked up rate. It certainly saved us and our lenders some shipping cost. Because fourteen requests (10.3\%) were canceled by the customers after they received our emails, letting us know that they no longer needed the items. Out of these 14 canceled requests by the customers, we were able to cancel 9 items (64.3\%) before they were shipped by the lenders. We will continue to monitor this practice to gauge its effectiveness.

We also added a format question in the loan request form:

In our loan request form, the first question is "Type of Request," we have a drop down that our customers can choose from: audiobook, Bluray, CD, DVD, eBook, print book, VHS, it is a required field.

We added another question right after, that is, Will you accept an alternate format of this item? (Figure 5) They must choose either yes or no. Underneath the question, we further explain what it means: that is, they will accept an eBook if our print copy is unavailable or vice versa.

This information is translated into the ILLiad client side, we use an empty field "Ariel" as an indicator. If there is a check mark next to Ariel, that means the customer will accept another format; if there is no check mark, the customer will only accept the format indicated.

In this example, the customer's request type is "Print Book," but they also indicated "Yes" that they would accept an alternate format, as the 


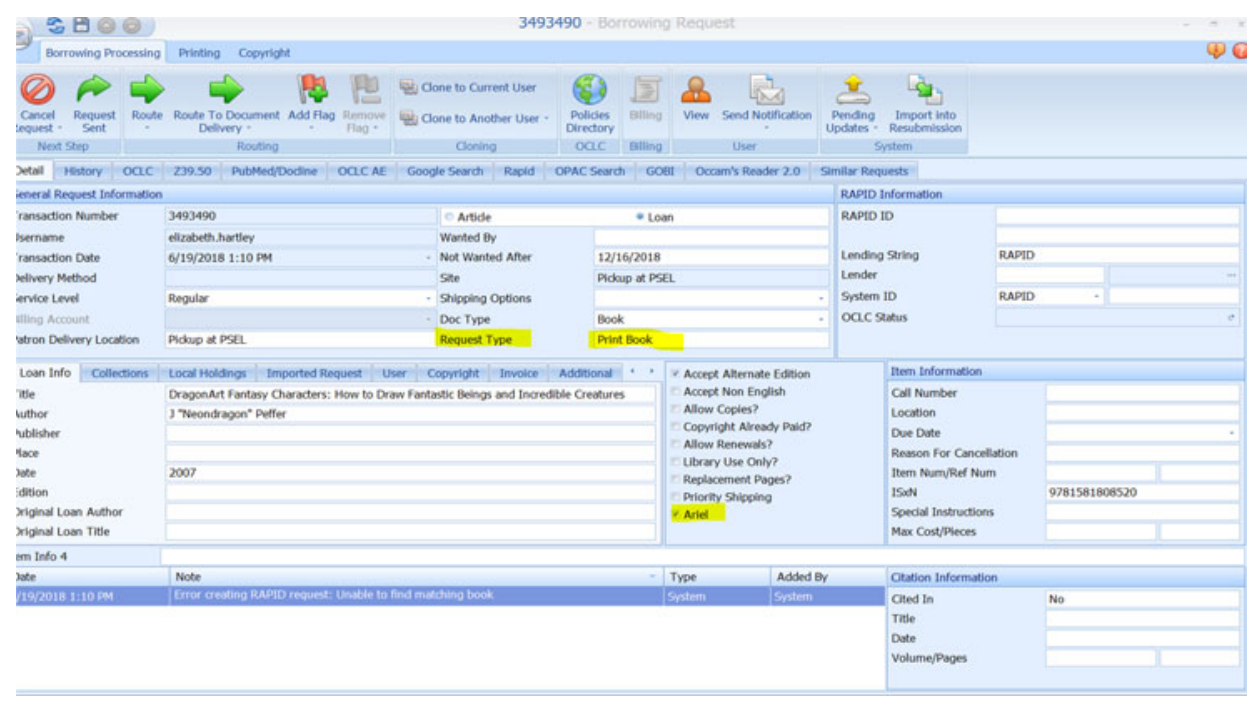

Figure 6. Format choice indicator in ILLiad.

mark next to the Ariel shows (Figure 6). So if we do not have a print book, or our print book is checked out, and we have an eBook version of the same title in our collection, we will give them the eBook link. If the customer indicated "No" alternate format, even if we have an eBook, we will not give them the eBook link. This cuts down the back and forth email confirmation with our customers as was mentioned earlier. We did receive some complaints from our customers when their request type choice was "Print Book," but we still sent the eBook link to them with the intention of promoting our eBook collections. However, this practice aggravated some customers who responded: "this practice amounts to library services assuming that customers don't really know the type of copy they are looking for even when they have chosen the 'print book' option in the relevant 'Type of Request' option field." Adding this question to the request form is our answer to our customers' feedback.

\section{Conclusion}

Resource sharing and document delivery activities can generate lots of data for us to ponder, digest, and analyze. This is just a small exercise that pertains to one institute's particular situation. However, we all can use this readily available and powerful data to guide us in making adjustments to our policy and workflow, pinpointing issues we have with the system.

Through this study, we realize that our customers submit duplicate requests that we still cannot catch when the requests submitted are days apart. Also, ILLiad does not "talk" to our Voyager circulation system (we will move to FOLIO in 2019). We hope for an app that allows both LMS 
(library management system) and ILL where they can "alert" to each other's activity. If a customer already received an item in one system, staff from the back end should be notified hence to cancel the same request still pending in the other system. Right now, we depend on the customer's own sense of responsibility-they have the ability to cancel duplicate requests they have ordered on purpose for timing's sake. However, many simply allow the duplicate item to arrive and do not pick up to check out.

Our findings further validate the known issue of discoverability. Many of our eBooks are in the subscription packages, and are not indexed in our EDS or catalog. As such, our users fail to find them. It also becomes a training issue for ILL managers to make sure that our staff are aware of our package subscriptions. It is particularly satisfying for the director of the department to receive such acknowledgement from our customer who wrote: "I spent half an hour going through google, HathiTrust, library's website and couldn't locate anything. Thanks for the link, exactly what I want."

Let data guide our policies.

\section{ORCID}

Zheng Ye (Lan) Yang (D) http://orcid.org/0000-0001-6757-7822

\section{References}

Blackburn, G., \& Tiemeyer, R. (2013). Textbooks and interlibrary loan. Journal of Interlibrary Loan, Document Delivery \& Electronic Reserve, 23(1), 5-18.

Gibson, T. (2008). Cancelled requests: A study of interlibrary lending. Journal of Access Services, 5(3), 383-389.

Grevatt, H. (2015). Developing a data narrative: Analyzing trends in an academic interlibrary loan department. Journal of Interlibrary Loan, Document Delivery \& Electronic Reserve, 25(3-5), 117-132.

Leon, L., \& Kress, N. (2012). Looking at resource sharing costs. Interlending \& Document Supply, 40(2), 81-87.

Munson, K. I., \& Savage, D. (2013). Interlibrary loan's efficacy in meeting students' expectations to acquire textbooks: results from a study conducted in a large research library. Journal of Interlibrary Loan, Document Delivery \& Electronic Reserve, 23(4-5), 191-200.

Murphey, R. M., \& Greenwood, J. T.. (2009). Feasibility of analyzing interlibrary loan requests to determine instruction needs. Journal of Access Services, 6, 359-387.

Reycraft, K. (2010). Interlibrary loan requests canceled due to availability: problem or opportunity?. Journal of Interlibrary Loan, Document Delivery \& Electronic Reserve, 20(1), 33-42.

Riha, E. C., \& LeMay, D. (2016). Saving students money with eBooks: a cross-departmental collaboration between interlibrary loan and course reserve. Technical Services Quarterly, 33(4), 386-408. 
Tolppanen, B. P., \& Derr, J. (2010). Interlibrary loan patron use patterns: an examination of borrowing requests at a midsized academic library. Journal of Interlibrary Loan, Document Delivery \& Electronic Reserve, 20(5), 303-317.

Yang, Z. Y., Hahn, D., \& Thornton, E. (2012). Meeting our customers' expectations: A follow-up customer satisfaction survey after 10 years of free document delivery and interlibrary loan services at Texas A\&M University Libraries. Journal of Interlibrary Loan, Document Delivery \& Electronic Reserve, 22(2), 95-110. 